\title{
The Human Comfort Level in an Energy-Saving Simulation Model of Office Building
}

\author{
Egils Dzelzitis ${ }^{1}$, Sandra Sidenko ${ }^{1 *}$ \\ ${ }^{1}$ Riga Technical University, Faculty of Civil Engineering, Institute of Heat, Gas and Water Technology, Riga, Latvia
}

\begin{abstract}
Currently high attention is drawn to the studies of the influence of pulsating flow to the heat transfer. Such unsteady flows can be created artificially or may appear during the operation of the thermal energy equipment. The purpose of this work is to perform numerical studies of the pulsating fluid flow effect supplied to a panel heating radiator on its heat output; and to determine the effect of pulsations of heat output on a human comfort level as well. Numerical modeling was prepared with CAD/CFD/HVAC complex of SolidWorks/FlowSimulation software. Where the complete system of Navier-Stokes equations and the energy equation were solved using the $k-\varepsilon$ turbulence model in a non-stationary formulation of the problem. Results of the numerical calculations showed that the periodic pulsating flow of the fluid in the heating radiator during operation, in comparison with the stationary mode, leads to increasing and decreasing in the thermal power of the radiator. But at the same time, with an average estimate, the thermal power with pulsations of the fluid's flow increases for about 10-15\% comparing with a stationary mode. Model of the office room in the considered operating mode is not comfortable; this conclusion is based on such criteria as operating temperature, PMV, PPD, identified in the numerical calculations process.
\end{abstract}

\section{Introduction}

Total energy consumption of buildings and structures in the construction sector today takes $41 \%$ of the total European Union (EU) energy consumption. For the heating and air conditioning it is used $85 \%$ of total energy consumption [1].

Therefore, the main target during design and construction of the energy-efficient buildings is the more efficient using of the energy resources spending to the energy supplying of the buildings. This can be achieved through the using of innovative solutions that are technically feasible, economically justified, and acceptable from an environmental and social point of view as well. The same time such solutions should not change the usual way of human lives [2-10].

For the most of buildings one of the promising ways to obtain an economic effect is intermittent heating process which is implemented using automated building management systems and is based on the European standard EN15232 [11].

However, this does not exclude the task of buildings energy efficiency increasing due to the optimization of the heat supplying systems, which may include:

- Increasing of the system's individual elements efficiency;

- Optimal heat sources capacity selection;

- Thermal circuit parameters optimization;

- Buildings thermal load profile optimization, etc.

Heat exchanging equipment of the buildings and structures is the main part of the heat supply systems and mostly determines their general technical and economic indicators. One of the main ways to increasing of the heat power devices efficiency in the future is the improvement of the heat exchanging equipment which can be realized through the introduction of effective heat transferring intensifications methods.

By heat transferring intensifications, increased amount of the heat, transferred through the unit of heat exchange surface, and achieving more favorable ratio between the transferred amount of heat and the pumped fluid power [5-16].

Special attention now is drawn to studies of pulsating flow influence on the heat transferring. Such unsteady flows can be created artificially or may appear during the operation of the thermal energy equipment.

Experimental studies of unsteady flows in the channels and heating radiators carried out in [17-22], showing flow pulsations that can significantly affect the hydrodynamics and heat transferring. Such non-stationary processes can be accompanied by increasing and decreasing of the heat transferring intensity.

However, the question of the effectiveness of this method is still open because where id a small knowledge of such processes. It is not clear how considered nonstationary processes in the channels and radiators installed in the living area with people will make an impact on the level of comfort.

The main target of this work is to carried out numerical studies of the pulsating fluid flow effect supplied to a panel heating radiator on its thermal power

* Corresponding author: Sandra Sidenko sandysid@inbox.lv 
and to determine the effect of thermal power pulsations on a people's comfort level as well.

Numerical modeling was carried out with CAD/CFD/HVAC complex of SolidWorks/FlowSimulation software [24]. Where the complete system of Navier-Stokes equations and the energy equation were solved using the $k$ - $\varepsilon$ turbulence model in a non-stationary formulation of the problem.

Due to the complexity of the numerical solution of the task and for reducing the calculation time, considered to a simplified three-dimensional model of office room and excluded such details as furniture, the influence of household equipment was not taken into account.

The accuracy of the obtained problem's solution was assessed based on the results of convergence of the thermal power of the P11 type panel radiator installed in the model of the room with the manufacturer's declared thermal power.

\section{Materials and methods}

\subsection{Office room model}

Geometric imitation 3D model of the office room was built with the help of SolidWorks CAD software. Due to the complexity of the numerical solution of the problem overall dimensions of the room were selected relatively small. Room area set $\mathrm{S}=3000 \times 3000 \mathrm{~mm}$, ceiling height $2500 \mathrm{~mm}$. Calculation of the thermal mode planned with the thermal conductivity of the building structures, and in this case the geometric model contains walls, ceiling, floor, window and door. 3D model of the office room is shown on Fig. 1.

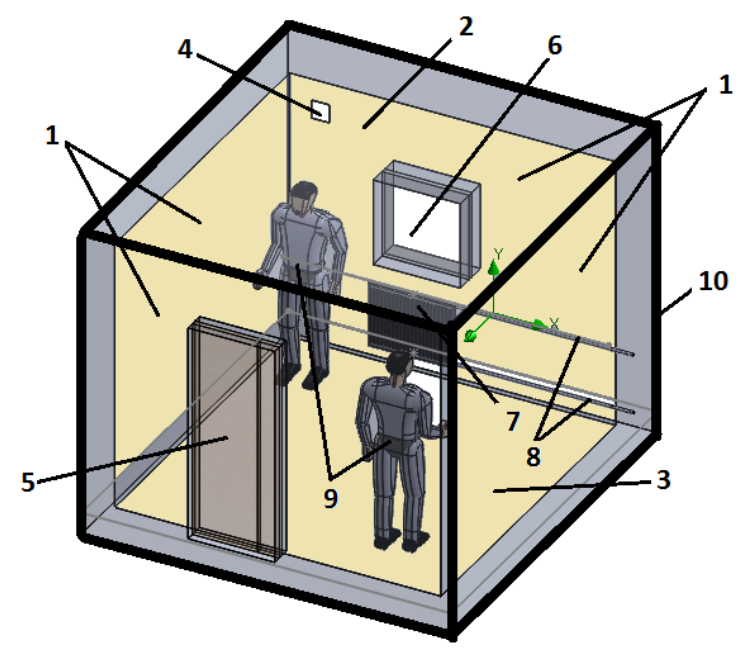

Fig.1. 3D model of the office room : 1 - walls; 2 - ceiling; 3 floor 4 - ventilation inlet; 5 - door; 6 - window; 7 - radiator; 8 pipes; 9 - humans; 10 - calculated domain.

All necessary initial and boundary conditions were set in the Flow Simulation part of the SolidWorks software package.

It is assumed that walls pos. 1 have brickwork with the following physical properties: density - $1700 \mathrm{~kg} / \mathrm{m}^{3}$, thermal conductivity $-0,62 \mathrm{~W} /(\mathrm{m} \cdot \mathrm{K})$, specific heat -800
$\mathrm{J} /(\mathrm{kg} \cdot \mathrm{K}$ ). Window (pos.6) and door (pos.5) were considered as a double-glazed windows, with the following physical properties: density - $2500 \mathrm{~kg} / \mathrm{m}^{3}$, thermal conductivity $-0,699 \mathrm{~W} /(\mathrm{m} \cdot \mathrm{K})$, specific heat $837 \mathrm{~J} /(\mathrm{kg} \cdot \mathrm{K})$. Room's air temperature is $15^{\circ} \mathrm{C}$.

The room is heated by the steel panel radiator type $\mathrm{P} 11$ (pos.7), with overall dimensions $600 \times 800 \mathrm{~mm}$, thermal power $861 \mathrm{~W}$ and operating pressure up to 10 Bar. The radiator is designed for the heated area up to $10 \mathrm{~m}^{2}$. Inner diameter of the inlet and outlet water pipes (pos.8) is 20 $\mathrm{mm}$. The radiator is made from stainless steel: density $7900 \mathrm{~kg} / \mathrm{m}^{3}$, thermal conductivity - $16.3 \mathrm{~W} /(\mathrm{m} \mathrm{K})$, specific heat $-500 \mathrm{~J} /(\mathrm{kg} \cdot \mathrm{K})$. 3D of the radiator is shown on Fig. 2.

Water is considered as a heat carrier in a heating system and radiator. For the case of a stationary flow the velocity of the water in the inlet is $\mathrm{V}=0.4 \mathrm{~m} / \mathrm{s}$ (top flow rate) with pressure $\mathrm{P}=5 \mathrm{Bar}$. Inlet flow temperature $80^{\circ} \mathrm{C}$, outlet flow temperature $-60^{\circ} \mathrm{C}$.

It should be noted here that due to the complexity of solving the unsteady Navier-Stokes equations and reducing of the estimated time, which can reach 36 hours and more. It was assumed that the outside temperature is negative, and in accordance to the Latvian building codes and rules in these conditions, the temperature of the heat agent supplying to the radiators should be $80^{\circ} \mathrm{C}$, return flow $-60^{\circ} \mathrm{C}$. At the same time, the air temperature in the room at the initial time was already $15^{\circ} \mathrm{C}$, but has not yet reached a comfort level of $20-21^{\circ} \mathrm{C}$. The pressure in the room is normal.

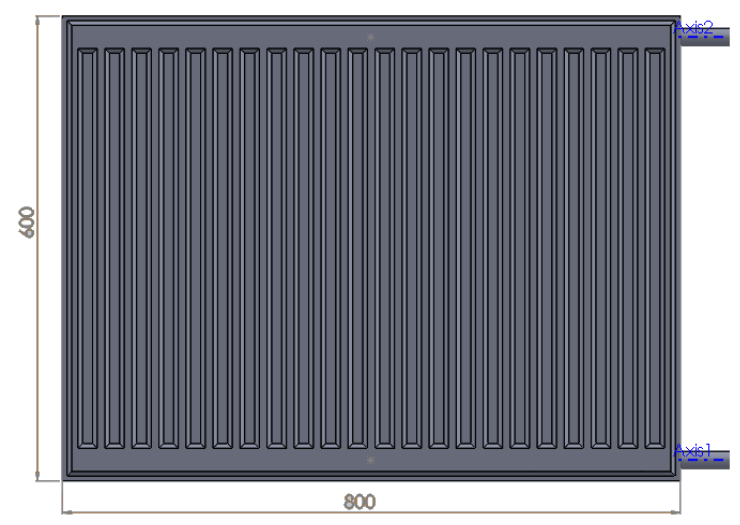

Fig.2. 3D model of the radiator.

To study of the flow pulsations effect on the heat transferring based on the model of periodical pulsating fluid in radiator with a sinusoidal velocity pulse which can be described by equation (1):

$$
\mathrm{V}(\mathrm{t})=0,4(1+\mathrm{A} \sin (2 \pi \mathrm{ft}))
$$

Where $t$ is time, $V(t)$ is the velocity, $A=1$ is the amplitude of the pulsations, pulsating frequency $f=5 \mathrm{~Hz}$. The time-averaged velocity equal to $V_{0}=0,4 \mathrm{~m} / \mathrm{s}$.

Dependence of the fluid flow rate $\mathrm{V}$ on time $\mathrm{t}$ at a pulsation frequency of the fluid flow of $5 \mathrm{~Hz}$ is shown on the graph on Fig. 3. The dashed line corresponds to the average flow velocity $\mathrm{V}_{0}=0.4 \mathrm{~m} / \mathrm{s}$, the solid line $\mathrm{V}(\mathrm{t})$ to equation (1). 


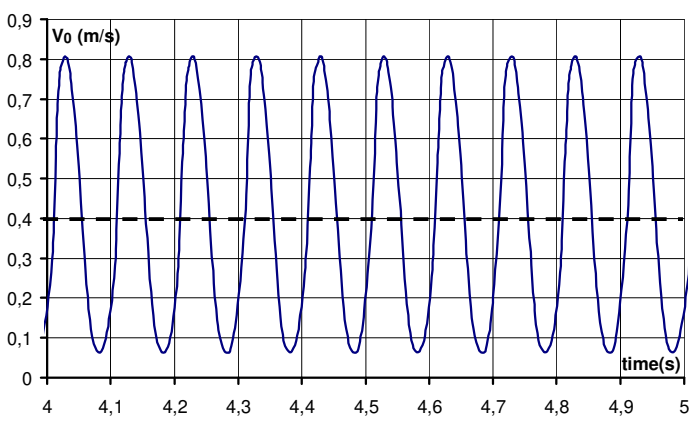

Fig.3. Graph of the dependence of the flow velocity V(t) at $\mathrm{f}=$ $5 \mathrm{~Hz}$.

The fresh air intake into the room is carried out through the ventilation hole 4 located on the wall and connected to the street. Overall dimensions of the ventilation hole is $170 \times 170 \mathrm{~mm}$, inlet flow $0,006 \mathrm{~m} 3 / \mathrm{s}$. The temperature of the incoming air is $15^{\circ} \mathrm{C}$. So, temperature on the inlet of the fresh air is equal to the initial temperature of the room.

There are two people in the room, on the peoples surface was set thermal power with level of $140 \mathrm{~W}$.

The geometric calculation model (Domain (pos.10)) is the same as the original room model. The condition is considered as an internal.

The considered model does not intend to describe a real object, since the main task is to identify the influence of thermal power pulsations on the comfort level of people in the room.

\subsection{Mathematical model}

The non-stationary Navier-Stokes equation, the energy equation (the first law of thermodynamics) and the equation of state [23, 24] are used for mathematical modelling of the motion of the medium and heat exchange. For turbulent flows the initial equations are averaged by the Reynolds method and additional stresses due to turbulent parameter pulsations are taken into account [23, 24]. The obtained unclosed system of equations is closed with the help of additional equations for the kinetic energy of turbulence $\mathrm{k}$ and dissipation of turbulence energy $\varepsilon$ in accordance with the known $\mathrm{k}-\varepsilon$ turbulence model [23]. The system of equations of conservation of momentum (4), mass (5) and energy (6), describing turbulent, laminar and transient flows of compressible fluid with heat exchange can be set as following:

$$
\begin{gathered}
\frac{\partial \rho u_{i}}{\partial t}+\frac{\partial}{\partial x_{j}}\left(\rho u_{i} u_{j}-\tau_{i j}\right)+\frac{\partial P}{\partial x_{i}}=F_{i} \\
\frac{\partial \rho}{\partial t}+\frac{\partial}{\partial x_{j}}\left(\rho u_{j}\right)=0 \\
\frac{\partial(\rho E)}{\partial t}+\frac{\partial}{\partial x_{i}}\left((\rho E+P) u_{i}+q_{i}-\tau_{i j} u_{j}\right)=F_{i} u_{i}+Q_{H}
\end{gathered}
$$

Two additional transport equations are used to show the turbulent kinetic energy $k$ and dissipation $\varepsilon$ :

$$
\begin{gathered}
\frac{\partial \rho k}{\partial t}+\frac{\partial}{\partial x_{i}}\left(\rho u_{i} k\right)=\frac{\partial}{\partial x_{i}}\left(\left(\mu_{l}+\frac{\mu_{t}}{\sigma_{k}}\right) \frac{\partial k}{\partial x_{i}}\right)+S_{k} \\
\frac{\partial \rho \varepsilon}{\partial t}+\frac{\partial}{\partial x_{i}}\left(\rho u_{i} \varepsilon\right)=\frac{\partial}{\partial x_{i}}\left(\left(\mu_{l}+\frac{\mu_{t}}{\sigma_{\varepsilon}}\right) \frac{\partial \varepsilon}{\partial x_{i}}\right)+S_{\varepsilon}
\end{gathered}
$$

where the source terms $\mathrm{S}_{k}(7)$ and $\mathrm{S} \varepsilon(8)$ are defined as:

$$
S_{k}=\tau^{R}{ }_{i j} \frac{\partial u_{i}}{\partial x_{j}}-\rho \varepsilon+\mu_{t} P_{B}
$$

$$
S_{\varepsilon}=C_{\varepsilon 1} \frac{\varepsilon}{k}\left(f_{1} \tau^{R}{ }_{i j} \frac{\partial u_{i}}{\partial x_{j}}+\mu_{t} C_{B} P_{B}\right)-C_{\varepsilon 2} f_{2} \frac{\rho \varepsilon^{2}}{k}
$$

Following Boussines assumption, the Reynolds-stress tensor (9) has the following form:

$$
\tau_{i j}^{R}=\mu_{t}\left(\frac{\partial u_{i}}{\partial x_{i}}+\frac{\partial u_{j}}{\partial x_{i}}-\frac{2}{3} \frac{\partial u_{l}}{\partial x_{l}} \delta_{i j}\right)-\frac{2}{3} \rho k \delta_{i j}
$$

The diffusive heat flux (10) is defined as:

$$
q_{i}=-\left(\frac{\mu_{l}}{\operatorname{Pr}}+\frac{\mu_{t}}{\sigma_{c}}\right) C_{P} \frac{\partial T}{\partial x_{i}}
$$

Upon analysing the conjugate heat exchange between the flow and the solid the heat transfer in solid is simulated by the known heat transfer equation [23]:

$$
\frac{\partial \rho e}{\partial t}=\frac{\partial}{\partial x_{i}}\left[\lambda_{s} \frac{\partial T}{\partial x_{i}}\right]+Q_{H},
$$

where $u_{i j}$ - the fluid velocity is a function of four independent variables $\mathrm{x}, \mathrm{y}, \mathrm{z}, \mathrm{t} ; P$ - the fluid pressure is a function of four independent variables $\mathrm{x}, \mathrm{y}, \mathrm{z}, \mathrm{t} ; \quad \rho$ - the fluid density; $F_{i}$ - total force acting on the mass unit; $E$ total energy of fluid mass unit; $Q_{H}$ - heat source per volume unit; $\tau_{i j}$ - viscous shear stress tensor; $i=x, y, z ; j=x, y, z$ - summing is made by subscripts; $\mu_{l}$ , $\mu_{t}-$ dynamic viscosity coefficient, turbulent viscosity coefficient; $\sigma_{k}, \sigma_{\varepsilon}$ - empirical constants; $\tau^{R}{ }_{i j}$ - stress tensor in Reynolds model; $g_{i}-$ components of gravitational acceleration in direction $x_{i} ; \mathrm{Pr}$ - Prandtl number; $C_{P}$ - specific thermal capacity at constant pressure; $\delta_{i j}$ - Kronecker symbol; $e$ - the specific heat; $T$ the temperature; $\lambda_{s}$ - the solid thermal conductivity.

The above equations (2)-(11) are highly general. Hereinafter, the authors concretize the constant values as well as the dependent and independent variables to solve the particular problems.

Equations (2)-(11) are solved numerically using the CFD software Flow Simulation [23]. Initial and boundary conditions for specific tasks are set in the Flow Simulation software in the volume and on the corresponding surfaces of the three-dimensional design model created in the CAD (computer-aided design) SolidWorks software. 
For numerical solve the system of equations (2)-(11), the Flow Simulation software uses the finite volume method with an adaptive rectangular grid. In the process of calculation the initial grid of finite volumes in the computational area is crushed automatically or according to the given rule in areas of assumed large gradients of each of the dependent variables or in areas of significant change in the curvature of the solid surfaces. All basic variables are referred to mass centers of control volumes. These cell-centered values are used for approximations. The integral conservation laws may be represented in the form of the cell volume and surface integral equation (12)-(13) [23]:

$$
\frac{\partial}{\partial t} \int U d v+\oint F d s=\int Q d v
$$

are replaced by the discrete form:

$$
\frac{\partial}{\partial t}(U \cdot V)+\sum_{\text {cell }} F \cdot S=Q \cdot V
$$

where $F$ - fluxes; $U$ - vector of physical parameters; $V$ cell volume; $S$ - cell surface area; $Q$ - mass forces.

For reducing of the numerical solution time in the places where high gradients are assumed, of course, the volumetric grid was crushed locally. This applies to the area of radiator, vent, and areas where people are.

For reasonable accuracy of the results of the solution in this work the order of 1.000.000-1.200.000 liquid and solid elements was required. Calculating grid of the office room is shown on Fig. 4.

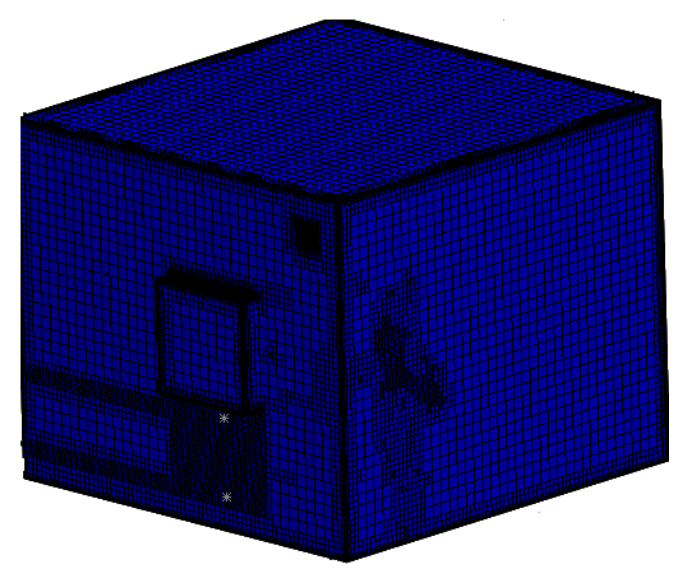

Fig.4. Calculating grid of the office room.

Note that in accordance with the calculation methodology any stationary problem is initially solved as non-stationary. The solution is considered to be found after its settings of time.

\subsection{Processing of the experimental data}

The HVAC Flow Simulation module of the SolidWorks software package has functionality to predict the parameters of the thermal sensation, discomfort level of people exposed to the environment [23].
Results of the numerical calculations generalizing a series of computer experiments were determined according to the following equations.

Predicted Unsatisfied Percentage (PPD) describes the proportion of people who experience discomfort under certain circumstances. This characteristic is probabilistic (values from 5 to $99,(9) \%$ ) and calculated by the equation (14):

$$
P P D=100-95 e^{\left(-0.03353 P M V^{4}-0.2179 P M V^{2}\right)}
$$

where PMV- Function Predicted Mean Vote [1].

Mean Radiant Temperature calculated by the equation (15):

$$
T_{r}^{4}=\frac{1}{4 \sigma} \int I_{\text {diffuse }}(\Omega) d \Omega+\frac{1}{4 \sigma} \sum I_{\text {sun }}
$$

where I diffuse - intensity of the diffuse (scattered) thermal radiation $\left(\mathrm{W}\left(\mathrm{m}^{2} \times \mathrm{rad}\right)\right)$;

Isun - intensity of the solar radiation $\left(\mathrm{W} \mathrm{m}^{2}\right)$;

$\sigma$ - Stefan - Boltzmann constant.

For the average radiation temperature calculating, the algorithm assumes that the blackness level of all faces in the calculation domain is 1 .

Operative Temperature is the homogeneous temperature of visually black environment in which a person receives the same amount of the heat through radiation in conjunction with convection, as if he was in an environment with an inhomogeneous temperature (16)

$$
T_{c}=\frac{T_{r}+T_{a} \sqrt{10 v}}{1+\sqrt{10 v}},
$$

where $T_{r}$ - average radiation temperature, ${ }^{\circ} \mathrm{C} ; T_{a}-$ air temperature, ${ }^{\circ} \mathrm{C} ; \mathrm{v}$ - air velocity, $\mathrm{m} / \mathrm{s}$.

\section{Results and discussion}

Results of the numerical calculations showed that for the stationary mode of the heating for the office room, the heat output $\mathrm{Q}_{0}$ of the radiator was 820 watts. This value is $5 \%$ lower than the known full-scale technical characteristics of P11 type radiators, but value is in the limits of the calculated error.

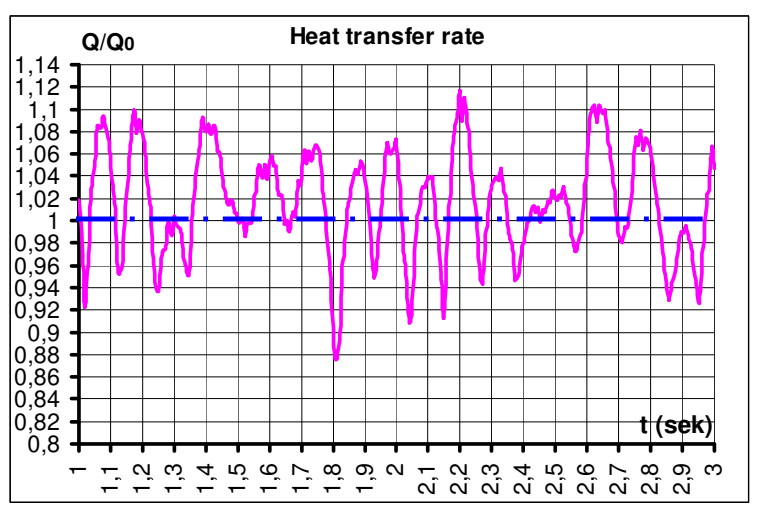

Fig. 5. Graph of the heat transfer rate $\mathrm{Q}_{/} \mathrm{Q}_{0}$ versus time $t$.

In the case of a periodically pulsating fluid in the radiator described by equation (1), its thermal power $\mathrm{Q}(\mathrm{t})$ 
changes over time. The graph of $\mathrm{Q} / \mathrm{Q}_{0}$ versus time $\mathrm{t}$ is shown on Figure 5. The dashed line corresponds to the stationary process with $\mathrm{V}_{0}=0.4 \mathrm{~m} / \mathrm{s}$, the solid line taking into account the non-stationary process of the heat transferring by the equation (1).

The graph shows that with a changing in the speed of the fluid in the radiator thermal power compared to the stationary mode can change averagely by $10 \%$, both upward and downward with maximal and minimal values.

Further, in this study investigated changing Operative Temperature in the radiator region, according to equation (16). Temperature parameters were taken at a given points with the corresponding coordinates in the space $\mathrm{x}, \mathrm{y}, \mathrm{z}$. The area under consideration was conditionally divided into the three zones: zone 1 - area with pipes for inlet and outlet of the heating fluid, zone 2 - radiator area, zone 3 area where people are located, there is no heating device and there is a ventilation hole on the top of the wall.

Results showed that in the first zone with respect to the stationary mode pulsations of the fluid flow do not significantly expose on the operating temperature $\mathrm{T}^{\circ} \mathrm{C}$. The second zone is characterized by increasing in operating temperature approximately $20 \%$ up, due to the pulsating changing in the heat power of the radiator. In comparison with the second zone it is observed decreasing of the operating temperature by an average $20-25 \%$ in the third zone.

The graph of the operative temperature $\mathrm{T} / \mathrm{T}_{0}$ is shown on Fig. 6. Here, the operating temperature $\mathrm{T}_{0}{ }^{\circ} \mathrm{C}$ is for the stationary mode and the $\mathrm{T}^{\circ} \mathrm{C}$ is for the pulsating flow mode in the radiator. The $\mathrm{x}$-axis represents the numbering of points corresponding to the coordinates in the space $\mathrm{x}$, $\mathrm{y}, \mathrm{z}$.

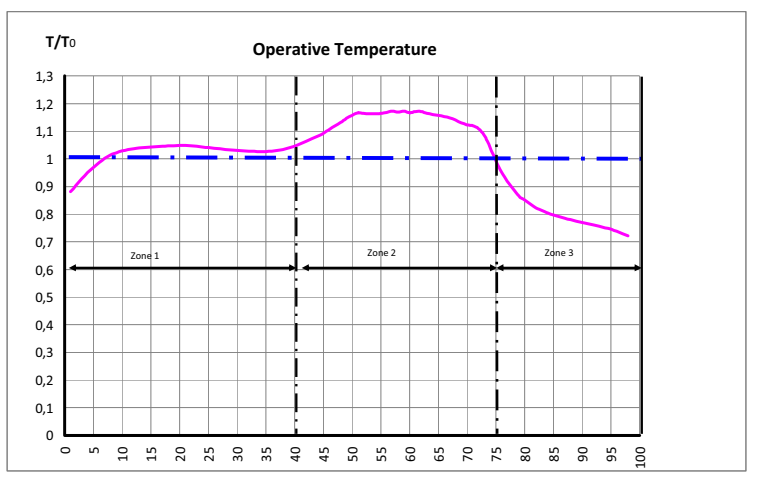

Fig.6. Operative temperature graph $\mathrm{T} / \mathrm{T}_{0}$.

Visualization of the operative temperature for the stationary mode is shown on the Fig. 7.

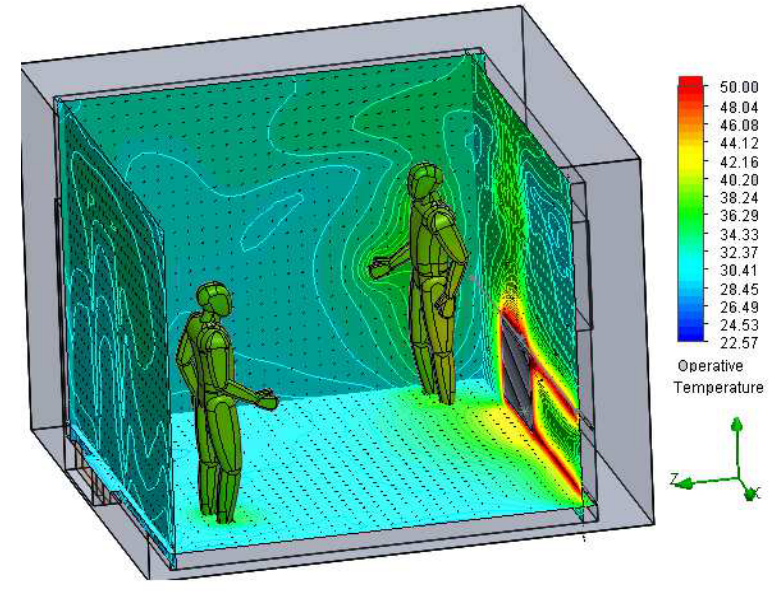

Fig.7. Operative temperature visualization for the room.

The human self-sense is determined by the heat balance in his body. In the numerical calculation process were determined environmental parameters such as average radiation temperature $\operatorname{Tr}$ and temperature $\mathrm{Ta}$, relative velocity $\mathrm{v}$ and air humidity. This allows us to predict thermal sensations Predicted Mean Vote (PMV average predicted rating) of people in the room according to the equation (15). Visualized picture of the Predicted Mean Vote in the room is shown in Fig. 8.

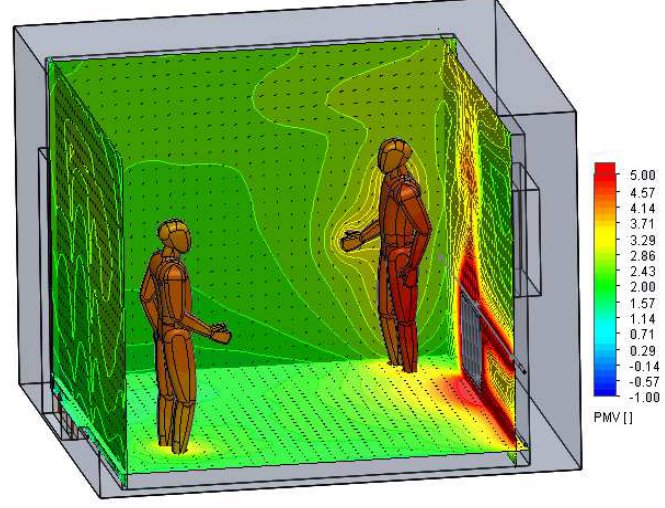

Fig. 8. Thermal feelings for the Predicted Mean Vote.

The figure shows that the maximum value of PMV is +5 and it is outside of the calibrated scale from -3 to +3 , that is the condition of a person near the radiator can be assessed as "very hot". For the opposite person from the zone between "warm" and "hot", that is, from +2 to +3 .

In the case of unsteady fluid flow mode PMV value of the person who is near radiator come up to +6 due to the increasing in heat output of the radiator.

Predicted percentage of unsatisfied (PPD) people indoors is the proportion of people with discomfort conditions in a given environment. This characteristic is probabilistic (with values from 5 to 99 , (9)\%) and is calculated on equation (14). Visualization of the Predicted Percent Dissatisfied (PPD) of the environment is shown in Fig. 9. 


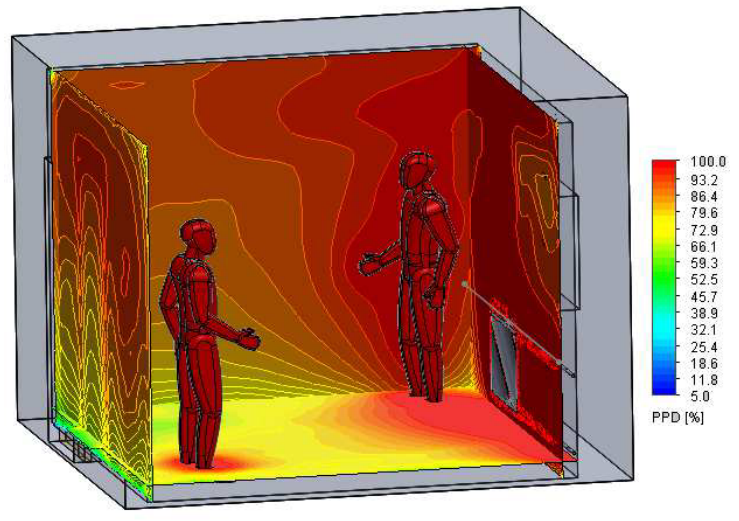

Fig.9. Predicted percentage of unsatisfied

As you can see, almost the entire room is uncomfortable and both people who are in it are not satisfied with the quality of their environment.

This can be explained by the high heating system temperature and the influence of pulsations of the heating media in the radiator, leading to an increasing of the thermal power. And as a consequence of the deterioration of climatic conditions affecting on the comfort level of people in the considered model of the room.

\section{Conclusions}

In this work many significant design and operational features with its affect on the level of comfort in the room were not taken into account. The main objective of this work was to identify the effect of the periodically pulsating fluid flow on the body power of the radiator, and as a result on the comfort conditions of the people in the room.

Revealed that comparing to the stationary mode the periodic pulsating flow mode of the fluid in the heating radiator leads to both increase and decrease in the heat power of the radiator during its work. But at the same time, with an average estimate, thermal power of the fluid pulsations increases about $10-15 \%$ up, compared to the stationary mode. This effect can allow to reduce the inlet temperature of the fluid or to install the heating radiators with lower thermal power to create the normal conditions of comfort.

Office room model in the considered operating mode is not comfortable. This conclusion is based on several criteria identified in the process of numerical calculations. The main area of discomfort is the area near the radiator. This applies to both modes under consideration while in the pulsating mode of work of the radiator the discomfort zone increases by approximately $10 \%$.

Cold air entering through the ventilation hole is ineffective. Therefore, in order to optimize further work it will be necessary to take into account additional optimization tasks associated with the installation of additional ventilation holes or air conditioners or other means.

This work allowed us to evaluate the capabilities of CAD/CFD/HVAC package of SOLIDWORKS / FlowSimulation software for applying to the tasks of related classes. It allows to take into account many parameters of fluid and solid as well, taking into account heat transfer and in an unsteady setting. Such capabilities allow getting almost any information on the basis of which we can evaluate situation and optimize processes associated with the design and operational features.

This research/publication was supported by Riga Technical University's Doctoral Grant program.

The research is prepared by the Ministry of Economics of the Republic of Latvia, project "Trends, Challenges and Solutions of Latvian Gas Infrastructure Development (LAGAS)", project No. VPP-EM-INFRA-2018/1-0003.

\section{References}

1. Communication from the Commission to the European Parliament, the Council, the European economic and social committee and the committee of the regions COM (2011) 109 of "Energy Efficiency Plan 2011" [Electronic resource].Access mode: (http://eurlex.europa.eu/LexUriServ/LexUri Serv.do?uri=COM:2011:0109:FIN:EN:PDF).08.03.2011.

2. «The impact of building automation and control functios on the energy effi ciency of buildings». Document Nr. CM110854en_02 2008. Siemens Switzerland Ltd.

3. «The business case for green building». 2013. World Green Building Council. European Standard EN 15232. "Energy Performance of Buildings. Impact of Building Automation, Controls and Building Management" [Electronic resource]. Access mode : (http://www.cres.gr/greenbuilding/PDF/prend/se t4/WI_22_TCapproval_version_prEN_15232_Integ rated_Building_Automation_Systems.pdf) - july 2007 [in English]

4. Borodinecs, A., Prozuments, A., Zajacs, A., \& Zemitis, J. (2019). Retrofitting of fire stations in cold climate regions. Magazine of Civil Engineering, 90(6), 85-92. doi:10.18720/MCE.90.8

5. Sergeev, V. V., Petrichenko, M. R., Nemova, D. V., Kotov, E. V., Tarasova, D. S., Nefedova, A. V., \& Borodinecs, A. B. (2018). The building extension with energy efficiency light-weight building walls. Magazine of Civil Engineering, 84(8), 67-74. doi:10.18720/MCE.84.7

6. Baranova, D., Sovetnikov, D., \& Borodinecs, A. (2018). The extensive analysis of building energy performance across the baltic sea region. Science and Technology for the Built Environment, 24(9), 982-993. doi:10.1080/23744731.2018.1465753

7. Zemite, L., Gerhards, J. Reliability evaluation of distribution systems (2014) 9th International Conference on Electrical and Control Technologies, ECT 2014, pp. 94-99. Cited 6 times. ISBN: 978163439803-9

8. Zemite, L., Kutjuns, A., Bode, I., Kunickis, M., Zeltins, N. Risk Treatment and System Recovery Analysis of Gas System of Gas and Electricity 
Network of Latvia (2018) Latvian Journal of Physics and Technical Sciences, 55 (5), pp. 3-14. doi: 10.2478/lpts-2018-0031

9. Zemite, L., Kutjuns, A., Bode, I., Kunickis, M., Zeltins, N. Consistency Analysis and Data Consultation of Gas System of Gas-Electricity Network of Latvia (2018) Latvian Journal of Physics and Technical Sciences, 55 (1), pp. 22-34. doi: 10.2478/lpts-2018-0003

10. Koposovs, A., Bode, I., Zemite, L., Dzelzitis, E., Odineca, T., Ansone, A., Selickis, A. and JASEVICS, A., 2019. Optimization of the Selection Method for Reconstruction of Outworn Gas Distribution Pipeline. Latvian Journal of Physics and Technical Sciences, 56(5), pp. 33-44. ISSN: 08688257, DOI: $10.2478 /$ lpts-2019-0029

11. Mahmood G. I., Ligrani P. M. Heat transfer in a dimpled channel: Combined influences of aspect ratio, temperature ratio, Reynolds number, and flow Structure. Intern. J. of Heat and Mass Transfer, 2002, vol. 45, iss. 10, pp. 2011-2020.

12. Kiselev N.A., Burtsev S.A., Strongin M.M. A procedure for determining the heat transfer coefficients of surfaces with regular relief. Measurement Techniques, 2015, vol. 58, no. 9, pp. 1016-1022. DOI: 10.1007/s11018-015-0835-7

13. Leontiev A.I., Dilevskaya E.V., Vinogradov Yu.A., Yermolaev I.K., Strongin M.M., Bednov S.M., Golikov A.N. Effect of vortex flows at surface with hollow-type relief on heat transfer coefficients and equilibrium temperature in supersonic flow. Experimental Thermal and Fluid Science, 2002, vol. 26 , iss. 5, pp. 487-497. DOI: 10.1016/S08941777(02)00157-7

14. A.G. Laptev, N.A. Nikolaev, M.M. Basharov Intensification methods and simulation of the heat and mass transferring processes. Reference guide.M.: «Heating engineer», 2011, 335 pp.

15. Galicejskij B.M. Thermal and hydrodynamic processes in oscillating flows / B.M. Galicejskij, YU.A. Ryzhov, E.V. YAkush. M., « Engineering », 1977. 256 pp.

16. Rajib Uddin Rony, Md Nahid Hasan and Md Ashiqur Rahman Laskar. Heat Transfer of Pulsating Turbulent Flow in Pipes. European Journal of Advances in Engineering and Technology, 2018, 5(8): 511-516 ISSN: 2394 - 658X

17. M. Embaye, R. K. Al-Dadah \& S. Mahmoud. The effect of flow pulsation on the heating performance of panel radiators in central heating systems: CFD analysis.

18. Advanced Computational Methods and Experiments in Heat Transfer XIIIWIT Transactions on Engineering Sciences, Vol 83, (C) 2014 WIT Press ISSN 1743-3533 (on-line). doi:10.2495/HT140031

19. Myhren, J. A. and Holmberg, S., Flow patterns and thermal comfort in a room with panel, floor and wall heating. Energy and Buildings, 40, pp. 524-536, 2008.

20. Berkan, A., Simulation of the heater test room defined by EN442 standard and virtual testing of different type of heaters (PhD thesis), 2011 Online. http://library.iyte.edu.tr/tezler/doktora/makinamuh/ T000858.pd

21. N.Sidenko, E.Dzelzitis "the method of numerical modeling of hydrodynamics and heat exchange in a channel with discrete roughness" International Scientific Journal „Mathematical Modeling” year II, ISSUE2/2018 ISSN (print) 2535-0986, ISSN (WEB) 2603-2929, 61-65 pp, http://stumejournals.com/journals/mm/2018/2

22. Egils Dzelzitis, Natalia Sidenko numerical simulation of heat exchange in discrete-rough channels at flow superimposed oscillations. Engineering for rural development. Jelgava, 22.24.05.2019. DOI: 10.22616/ERDev2019.18.N203

23. Alyamovsky A.A. and others. SolidWorks 2007/2008. Computer modeling in engineering practice. // BHV- Petersburg, Saint - Petersburg, 2008.

24. SOLIDWORKS/Flow Simulation version 2018 